Perspective essay

\title{
Linking research to practice: The landscape as the basis for integrating social and ecological perspectives of the rural
}

\author{
T. Pinto-Correia ${ }^{\mathrm{a}, *}$, L. Kristensen ${ }^{\mathrm{b}}$ \\ a ICAAM - Instituto de Ciências Agrárias e Ambientais Mediterrânicas, Universidade de Évora, 7000 Evora, Portugal \\ ${ }^{\mathrm{b}}$ Department of Geosciences and Natural Resource Management, University of Copenhagen, Denmark
}

\section{H I G H L I G H T S}

- Validates innovative and hybrid research on rural processes.

- Strengthens the landscape base approaches when addressing these rural processes.

- Proposes a conceptual framework that can guide hybrid research designs.

- Is based not in one single study but many years research development by two different teams in two different countries of Europe.

\section{A R T I C L E I N F O}

\section{Article history:}

Received 19 July 2012

Received in revised form 11 July 2013

Accepted 11 July 2013

Available online xxx

\section{Keywords:}

Landscape

Rural paradigms

Conceptual framework

Post-productivism

Transitions

\begin{abstract}
A B S T R A C T
The rural spaces in Europe are undergoing complex processes of transition, at multiple scales, and rhythms. In order to grasp and understand the changes occurring, the need emerges for new, conceptual approaches that make it possible to combine the different factors that shape spaces. Recent, literature on the multifunctional character of rural spaces and their transition pathways shows the, need for spatially based approaches, where the natural characteristics of a landscape are combined, with the socio-economic and cultural drivers that affect its changes. Experience shows how practical, questions on the changes affecting the rural, addressed by society to the scientific community, are of a, new character and require novel research approaches. This paper argues that landscape based, approaches can be useful basis for the required conceptual innovation. The paper presents and, discusses a set of examples of practice driven research developments, in contrasting regions of Europe. And it proposes a conceptual model which aims to contextualize empirical research driven by, problems set up in practice, and combining the ecological and structural dimensions with the socioeconomic, and cultural ones, all converging in the rural landscape, at multiple scales. The landscape, as, the spatial entity, in its material and immaterial dimensions, is presented in this paper as the most, comprehensive basis for the required step forward. This does not mean a disciplinary landscape, analysis revisited, but a new multi-scale and multi-domain place based approach, where the place is, the rural landscape.
\end{abstract}

(c) 2013 Elsevier B.V. All rights reserved.

\section{Introduction}

Transition theory suggests that a spatial, temporal, and structural co-existence of processes of transition from productivism to post-productivism is occurring in rural areas in Europe (Wilson, 2007), resulting in an increasing diversification of rural space (Berkel \& Verburg, 2011; Pinto-Correia \& Breman, 2009). Although agriculture and its role in production remains at the center of a maelstrom of issues surrounding food safety, environmental balance, and climate change, there is an increasing expectation by

\footnotetext{
* Corresponding author. Tel.: +351 266760885

E-mail addresses: mtpc@uevora.pt (T. Pinto-Correia), lokr@life.ku.dk (L. Kristensen).

society of other goods and services provided by rural space (de Groot, 2010, Chap. 1; Selman, 2009). These emerging dimensions are linked to the involvement of a wider community of actors at multiple scales of governance, increasing the social complexity of rural space (Barbieri \& Valdivia, 2010; Marsden \& Sonnino, 2008). Multifunctionality is thus an issue not only of diversification in farming but also of a change in paradigm for the management of the entire rural space (Domont, 2011; Selman, 2009; Wilson, 2009).

The local landscape is the spatial entity in which various drivers and demands meet (Selman, 2009). The landscape is understood here as the material expression of the dynamic and complex interaction of natural and cultural factors in a given place, as seen by an observer (Bastian \& Steinhardt, 2002; Council of Europe, 2000). However, the landscape is increasingly seen as an economic resource that can support rural development and enhance the 
multifunctional value of farms (Dissart \& Vollet, 2011). Those involved in the everyday management of the rural landscape, such as farmers, technical advisors, administration staff, and policy makers, are therefore faced with new challenges arising from the change in the relative emphasis from commodity to noncommodity land outputs (Dramstad \& Fjellstad, 2011; Mather, Hill, \& Nijnik, 2006).

New research questions are emerging, including (Beunen \& Opdam, 2011; Deconchat et al., 2007; Domont, 2011; Marsden \& Sonnino, 2008; Nassauer, 2011; Pelosi, Goulard, \& Balent, 2010; Satzman, Head, \& Stenseke, 2011) the combination of different demands and decision-makers in the same space, the shift from a sectorial to a territorial and place-based perspective on management, the new roles of farming and the on-farm management of ecological processes, decisions about conservation goals in terms of what should be preserved and what should be left to change, the possible viability of the rural space without farming, and the appropriate scale of intervention.

A review of the literature reveals that research on the processes affecting rural space has mostly overlooked the spatial dimensions of processes related to the territorial context (Marsden \& Sonnino, 2008; van der Ploeg, 2009; Wilson, 2007), such as the bio-physical characteristics and the cultural features of the landscape, including the environmental constraints, ecological capital, and territorial embeddedness of the social sphere, economic activities, and farming. In landscape-based research, the concern for interdisciplinarity is not new and has been addressed in relation to the understanding of processes affecting rural landscapes (Domon, 2011; Musachio, Ozdenerol, Bryant, \& Evans, 2005; Tress, Tress, \& Fry, 2005). There has been a growing concern over the last two decades about conceptualizing the landscape and its changes and expressing through conceptual frameworks the complex interactions between drivers at multiple scales and the resulting patterns and changes in land use and land cover (Bürgi, Straub, Gimmi, \& Salzmann, 2010; Hersperger, Gennaio, Verburg, \& Bürgi, 2010; Paquette \& Domon, 2001; Stenseke, Lindborg, Dahlberg, \& Slatmo, 2012). Resilience theory and the study of socio-ecological systems contribute significantly by focusing on the interplay between ecological and socio-economic factors and emphasizing the need to consider this interplay to understand changes in land use (Deconchat et al., 2007; Plieninger \& Bieling, 2012). Nevertheless, there is a lack of updated conceptualization concerning the landscape in the transition from productivism to post-productivism as well as its new role in combining the drivers of countryside management: production, consumption, and conservation (Selman, 2009; Wiggering et al., 2006; Holmes, 2012). There is also a lack of new conceptual backgrounds that support understanding, measuring, and overcoming the scale and goal mismatch between management at the farm level and the demand for public goods and services at the landscape level (de Groot, 2010, Chap. 1; Plieninger \& Bieling, 2012; Selman, 2012).

Considering the above-mentioned challenges for research, the goal of this paper is to propose a research framework for the study of the rural space and rural change supported by the strength of the spatial perspective and with the landscape as the center of interlinking rural processes. The paper argues that the landscape, as a spatial entity, in its material and intangible dimensions is the most comprehensive basis for the assessment and understanding of the ongoing transition processes in the rural areas of Europe and for the required integration of disciplinary positioning and approaches.

First, the paper describes the multiple transition processes occurring in the rural space and identifies the core problem of a lack of research constructions able to address their multiple dimensions. Then, based on rich evidence from contrasting landscapes in Europe, this paper presents lessons learned about research pathways resulting in problem-solving knowledge, which is societally sound and produces advances in science. Finally, this paper derives a comprehensive framework for understanding the rural landscape that can support the design of novel and integrative research.

The importance of this paper has emerged as the authors have verified that new approaches developed or still in progress must be made explicit to be more widely recognized by the scientific community (Beunen \& Opdam, 2011; Dramstad \& Fjellstad, 2011). The findings in the paper are not new research findings but are the result of many years of research by both authors and collaborators that have produced the following long-term and shared reflection on lessons learned, progress, scientific novelty, and practical applications. This research builds on established and time-proven knowledge drawn from contrasting case studies in European landscapes.

In a wider sense, this paper aims to contribute to greater awareness among scholars who study the dynamics and management of rural landscapes about the role, the potential, and the specific contribution of the research they produce. It is also expected to contribute to the development of greater acceptance in the scientific world of the added value of this type of problem-oriented and integrated research approach.

\section{Rural landscapes under change and the multifunctional demand}

\subsection{Rural areas under change}

For decades, the rural landscapes in Europe have undergone rapid and sometimes radical change in different directions and at different speeds. The landscapes reflect what is occurring worldwide; the same multiple changing trends at multiple scales are observed in many other regions of the world. The factors of change, including productivist and post-productivist trends, are combined in various ways (Robinson, 2008; Wilson, 2007) and have occurred in diverse directions and intensities in individual regions and localities (Berkel \& Verburg, 2011). In the same location, divergent processes may occur side by side, leading to greater complexity in the changing patterns (Short, 2008). Productivism is broadly conceptualized on the basis of an industrially driven agriculture, maximizing production and farm modernization. Postproductivism has been used as a much fuzzier concept (Mather et al., 2006; Selman, 2009). It corresponds to a move away from the productivist paradigm and it is related to all of the emerging social demands that involve agriculture and that range from the environmental balance to identity, cultural heritage, and social equity, resulting in a multifunctional understanding of rural landscapes and agriculture (Renting et al., 2009). This combination of changing processes has resulted in growing spatial variation in rural areas (Berkel \& Verburg, 2011; Bürgi et al., 2010; Lambin \& Meyfroidt, 2010), with some landscapes becoming more homogeneous due to processes of simplification of land use and land cover, whereas others are developing into more complex patterns.

The transformations at stake are connected partly to the restructuring processes in the agricultural sector (Holmes, 2012), including intensification and extensification, specialization, and concentration, leading to remarkable changes in land use, offfarm input (energy, capital), and the use of human capital. These transformations are also related to urbanization, including urban sprawl and infrastructure development as well as changes in broad socio-economic processes. These changes have resulted in fluxes and relocations of people and activities, mostly in the sense of a concentration in urban areas and a progressive emptiness of rural districts. In some areas, these changes have involved counterurbanization (Primdahl \& Swaffield, 2010), which implies that new power relations are evolving locally and that new actors are becoming involved in the management of land (Gill, Klepeis, \& Chrisholm, 
2010). Rural landscapes have changed from a production and living space in past decades to a space of consumption and conservation (Holmes, 2012; Wilson, 2007). These changing processes are creating new possibilities and tensions.

In regions where biophysical and structural conditions for agriculture are favorable, intensification and modernization have occurred for decades, along with the productivism paradigm (Primdahl \& Swaffield, 2010). The landscape has undergone a process of simplification and a loss of place-based qualities. At the same time, the social demand for non-commodity functions has typically increased in these regions, leading to a new awareness of the value of landscapes and the need to consider outcomes other than production. Thus, a more homogeneous landscape may be associated with a strong post-productivist discourse and pressure for a transition in farming practices, which may lead to renewed landscape diversity (Wilson, 2007). This is the situation that has been occurring in Northwestern Europe.

In Southern Europe, on the other side, as in many areas of the globe with limited conditions for industrial agriculture, agricultural systems have often not even entered the productivist phase, let alone moved toward post-productivism (Perfecto, Vandermeer, \& Wright, 2010; Robinson, 2008). The limitations of industrial agriculture may be related to natural conditions, location, structural constraints, lack of access to technology, or socio-political history. In these areas, there is often a specific landscape character that is highly valued by society due to its potential for non-commodity functions, but not necessarily leading to a transition in terms of discourse and management practices. If the non-commodity demand were acknowledged and compensation mechanisms were established, some of these landscapes could be maintained through new forms of management and compensation, corresponding to emerging farming paradigms (Barbieri \& Valdivia, 2010; Oreszczyn, Lane, \& Carr, 2010; van der Ploeg, 2009). Otherwise, the former agricultural systems may decay or disappear, replaced by new land use systems or left to renaturalization if the post-productivism discourses are not reflected in practice.

Many possible combinations may exist between the abovedescribed extremes, reflecting differences in the landscape per se, its biophysical context, and its history of human occupation as well as in the present balance between production, consumption, and conservation drivers (Holmes, 2012; van Eupen et al., 2012).

\subsection{From farming to multiple stakeholders and functions}

Transition trajectories in agriculture depend on farmers' decisions. Some farmers continue to follow the productivist model, others introduce innovations and combined activities on the farm, and others opt for new farming paradigms as a re-invented peasant-like lifestyle (Pinto-Correia, Menezes, \& Barroso, 2013; Pinto-Correia et al., 2013; van der Ploeg, 2009). Many of these options correspond to new profiles of farmers, or land managers that did not exist some decades ago. There are also non-farmers who address new activities related to the land, such as leisure and recreation, or social activities that benefit from the specific qualities of the rural space (e.g., the integration or re-education of excluded groups). Others choose to live in rural areas, developing other types of economic activities with a local link, such as locally based services or the maintenance of the cultural heritage, or without such a link, such as intellectual and artistic work for the external public. These rural inhabitants may not relate to farming directly, but they are users of the landscape, interact with farmers, and are part of the social and cultural life that makes it possible for farmers and their families to live in the rural space. As such, new and diversified stakeholder groups emerge, and some of the older ones adopt new roles (Domon, 2011; Pinto-Correia \& Breman, 2009; Wilson, 2007). The need to grasp this new complex reality leads to an emphasis on multifunctionality as a territorial concept more than a farming concept. More than ever, the management of the land is related to a complex web of social and economic relations, including the farmer and other land managers, the local community, the local authorities, and centrally placed policymakers.

\subsection{The importance of place}

The role of the local biophysical context cannot be underestimated. Not all agricultural productions are possible in every natural condition, and not all goods and services can be supported or developed in every landscape independently of the will and entrepreneurship of the involved stakeholders. Further, even if it is possible to change the property structure and settlement arrangements, these are quite stable conditions of each particular landscape. The biophysical and structural constraints and potentialities are determinants of the use of the land (Hersperger et al., 2010). Thus, there is an issue of place, which has a central role in the balance of production, consumption, and conservation. Reconnecting to the landscape, as an expression of the local context, is the way forward to understand the reshaped balance of actors and activities in the rural space (Selman, 2012; Stenseke et al., 2012).

\section{Lessons learned from multiple empirical studies}

Considering extreme situations highlights the range of new challenges derived from the multiple transitions occurring in rural spaces. The research developed by the two authors in two contrasting countries of Europe, Denmark and Portugal, makes it possible to develop two complementary narratives on the processes that shape rural landscapes today and the comprehensive perspective needed for their analysis.

Table 1 summarizes the major dimensions of the different studies from which a conceptual framework for the analysis of transition processes in rural areas has emerged. The conceptual framework is presented in the next section.

Agricultural landscapes in Denmark are some of the most intensively used in Europe, with approximately $90 \%$ of the land in arable cultivation. These landscapes are mainly produced by a modern and industrialized agriculture that is effectively linked to global food markets and that contributes significantly to the national budget (Primdahl, 2011). Pork production may serve as an example: since 1970 , production has doubled, and Denmark has the largest production of pigs per capita in the world. More than $85 \%$ of pork is exported, mainly to European markets, but increasingly to more remote markets. An increasing portion of the feed is imported, partially decoupling the production from the local landscape. However, the land and production are still linked through environmental regulations on manure and nitrogen (Kristensen, 2003; Kristensen, Thenail, \& Kristensen, 2004). The successful development of Danish agriculture is linked to a long tradition of cooperative organization, close public-private partnerships, and few natural constraints on land cultivation.

The reclamation of permanent grassland and other seminatural areas, drainage of wetlands, and the removal of hedgerow, stonewall, and other field structures are well-known negative landscape consequences of the development of agriculture that have been frequently reported since the 1980s (Agger \& Brandt, 1988). Other important structural implications of the agricultural modernization process include farm enlargement through the amalgamation of farm lands from different farm properties, leaving thousands of small farm houses (which are superfluous for modern agriculture) accessible for users and uses other than traditional famers and productive farming. Since the mid-1980s, agricultural landscapes in Denmark have been framed by such contradictory 